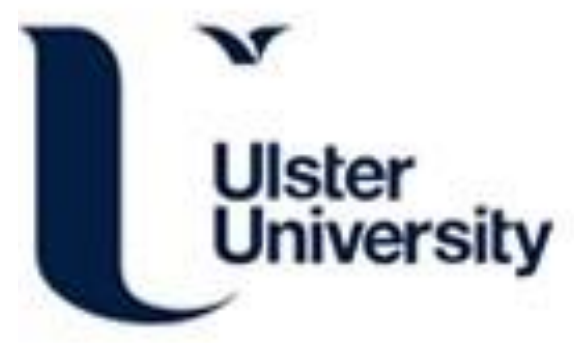

\title{
Experimental investigation and numerical modelling of the fire performance for epoxy resin carbon fibre composites of variable thicknesses
}

Fateh, T., Zhang, J., Delichatsios, M. A., \& Rogaume, T. (2017). Experimental investigation and numerical modelling of the fire performance for epoxy resin carbon fibre composites of variable thicknesses. Fire and Materials, 41, 307-322. https://doi.org/10.1002/fam.2381

Link to publication record in Ulster University Research Portal

Published in:

Fire and Materials

Publication Status:

Published (in print/issue): 01/01/2017

DOI:

10.1002/fam.2381

\section{Document Version}

Author Accepted version

\section{General rights}

Copyright for the publications made accessible via Ulster University's Research Portal is retained by the author(s) and / or other copyright owners and it is a condition of accessing these publications that users recognise and abide by the legal requirements associated with these rights.

\section{Take down policy}

The Research Portal is Ulster University's institutional repository that provides access to Ulster's research outputs. Every effort has been made to ensure that content in the Research Portal does not infringe any person's rights, or applicable UK laws. If you discover content in the Research Portal that you believe breaches copyright or violates any law, please contact pure-support@ulster.ac.uk. 


\section{Experimental Investigation and Numerical Modelling of the Fire Performance For Epoxy Resin Carbon Fiber Composites Of Variable Thicknesses}

T. Fateh ${ }^{1}$, J. Zhang ${ }^{1}$, M. Delichatsios ${ }^{1}$ and T. Rogaume ${ }^{2}$.

1) FireSERT, School of Built Environment \& Research, Institute of Built Environment University of Ulster, Newtownabbey, BT37 0QB, United kingdom.

2) Institut Pprime, CNRS, Université de Poitiers, ISAE-ENSMA, F-86962 Futuroscope Chasseneuil, France.

* Corresponding author: Phone: +44 (0) 2890368766

Fax: (+44) (0)28 90368726, Email: t.fateh@ulster.ac.uk 


\section{Abstract}

This paper applies a unique integrated approach to determine the flammability properties of a composite material (Epoxy with carbon-fiber) and compares its fire behavior at two different thicknesses (2.1 mm and $4.2 \mathrm{~mm}$ ) by performing small scale (TGA/FTIR) and meso-scale tests (Cone Calorimeter). For small scale tests, experiments were conducted in nitrogen using thermo-gravimetric analysis (TGA) coupled to gas analysis by Fourier Transform Infrared Radiation (FTIR).These results allow the determination of thermal stability, main degradation temperature and main gaseous emissions released during the thermal degradation. For mesoscale tests, experiments were carried out using a cone calorimeter with sample dimensions of $100 \times 100 \mathrm{~mm}$ at five heat fluxes $\left(30,40,50,60\right.$ and $\left.70 \mathrm{~kW} / \mathrm{m}^{2}\right)$. The results show that the ignition time increases with an increase in the thickness of the material. Relative hazard classification of the fire performance of the current composites has also been compared with other materials using parameters obtained elsewhere. In addition, the effective ignition, thermal and pyrolysis properties obtained from the ignition and mass loss rate experiments for the $4.2 \mathrm{~mm}$ thick samples were used in a numerical model for pyrolysis to predict well ignition times, back surface temperatures and mass pyrolysis rates for all heat fluxes as well as for the $2.1 \mathrm{~mm}$ thick samples. Note that the ignition temperature obtained in the cone agrees with the main degradation temperature in the TGA. The flammability properties deduced here can be used to predict the heat release rate for real fire situations using CFD modelling.

KEYWORDS: Cone calorimeter, TGA, Epoxy composite, Thermal degradation, Pyrolysis, Gaseous emissions, FTIR.

\section{NOMENCLATURE}

\begin{tabular}{|l|l|l|l|}
\hline A & pre-exponential factor $\left(\mathrm{s}^{-1}\right)$ & $\mathrm{c}$ & Specific heat $\left(\mathrm{J} \cdot \mathrm{kg}^{-1} \mathrm{~K}^{-1}\right)$ \\
\hline TRP & Thermal Response Parameter $\left(\mathrm{kW} \cdot \mathrm{s}^{1 / 2} \cdot \mathrm{m}^{-2}\right)$ & $\mathrm{E}$ & \\
\hline TSP & Total Smoke Production $\left(\mathrm{m}^{2}\right)$ & Activation energy $\left(\mathrm{kJ} \cdot \mathrm{mol}^{-1}\right)$ \\
\hline TGA & Thermogravimetric Analysis & A & Thermal diffusivity $\left(\mathrm{m}^{2} \cdot \mathrm{s}^{-1}\right)$ \\
\hline$I$ & Thermal inertia $\left(\mathrm{J}^{2} \cdot \mathrm{m}^{-4} \mathrm{~K}^{-2} \mathrm{~s}^{-1}\right)$ & $\delta$ & Thermal depth $(\mathrm{m})$ \\
\hline SMLR & Specific mass-loss rate $\left(\mathrm{g} \cdot \mathrm{m}^{-2} \cdot \mathrm{s}^{-1}\right)$ & $\rho$ & Density $\left(\mathrm{kg} \cdot \mathrm{m}^{-3}\right)$ \\
\hline
\end{tabular}




\begin{tabular}{|l|l|l|l|}
\hline $\mathrm{h}$ & Heat transfer coefficient $\left(\mathrm{W} \cdot \mathrm{m}^{-2} \mathrm{~K}^{-1}\right)$ & $\alpha$ & Diffusivity $\left(\mathrm{m}^{2} . \mathrm{s}\right)$ \\
\hline $\mathrm{k}$ & Thermal conductivity $\left(\mathrm{W} \cdot \mathrm{m}^{-1} \mathrm{~K}^{-1}\right)$ & $\varepsilon$ & Emissivity \\
\hline $\mathrm{t}$ & Time (s) & $\Delta H_{C}$ & Heat of Combustion $\left(\mathrm{kJ} \cdot \mathrm{g}^{-1}\right)$ \\
\hline $\mathrm{Y}$ & Yield $\left(\mathrm{g}_{\text {gas }} / \mathrm{g}_{\text {sample }}\right)$ & $(\dot{m})$ & Mass Flow Rate $\left(\mathrm{g} . \mathrm{s}^{-1}\right)$ \\
\hline $\mathrm{X}$ & Mole Fraction of Species $(-)$ & $q_{\text {int }}$ & Heat flux intercept $\left(\mathrm{kW} . \mathrm{m}^{-2}\right)$ \\
\hline EHC & Effective Heat of Combustion $\left(\mathrm{kJ} . \mathrm{g}^{-1}\right)$ & erfc $(x)$ & complementary error function \\
\hline $\mathrm{CHF}$ & Critical Heat Flux $\left(\mathrm{kW} \cdot \mathrm{m}^{-2}\right)$ & Subscripts \\
\hline FTIR & Fourier Transformed InfraRed spectroscopy & 0 & Initial, ambient \\
\hline MLR & Mass Loss Rate $\left(\mathrm{g} . \mathrm{s}^{-1}\right)$ & $\mathrm{b}$ & Specie \\
\hline TML & Total Mass Loss $(\mathrm{g})$ & ig & Ignition \\
\hline HRR & Heat Release Rate $\left(\mathrm{kW} . \mathrm{m}^{-2}\right)$ & eff & Effective \\
\hline THR & Total Heat Release $\left(\mathrm{MJ} . \mathrm{m}^{-2}\right)$ & $\mathrm{e}$ & Transferred to the surface \\
\hline
\end{tabular}

\section{INTRODUCTION}

Composites of carbon fibers with a polymer resin are widely used recently as alternatives to metals in the aerospace industry. The composite properties such as light weight, mechanical performance, cost and environmental impact (life cycle assessment) are advantageous factors to the aircraft designer.

However, one of the main safety issues in using composite materials is their flammability. Furthermore, smoke and toxic gases emitted can cause hazards to humans and limit the visibility thus impeding the evacuation from an aircraft in case of a fire. Thus, the challenge requires attaining multifunctional composites with high-performance mechanical properties and acceptable flame resistance levels at the same time [1].

Apparatus to measure and deduce the flammability properties during the thermal degradation and burning of materials include a) the cone calorimeter [2] in meso-scale, and b) the TGA/FTIR [3] in micro-scale. TGA (Thermo-Gravimetric Analysis) is a traditional method to investigate thermal degradation by measuring the weight loss of mg quantities at different heating rates [3]. Fourier transformed infrared spectroscopy of the emitted gases combined with TGA (TGA-FTIR) is one of the most useful methods to better understand thermal 
degradation of solid materials because this technique can provide an understanding about the chemical reactions that can occur during the thermal decomposition [3].

A large database of information is already available on the time to ignition, heat release rate, and smoke toxicity properties of several composite materials used in aircraft or other structures [4-18]. Moreover, several researches investigated the behaviour of the resin alone and the resin with Nomex fabric combination using a cone calorimeter, others investigated the thermal degradation with or without a fire retardant treatment layer. In this sense, a study conducted by [4] shows that the thickness has an influence on the fire performance of the foam and fabric combinations [4].

The present study investigates the flammability properties of a carbon-fiber/epoxy composite developed for modern aircraft at two different thicknesses by conducting micro-scale and meso-scale experiments in order to fully comprehend the thermal degradation of the composite materials. For micro-scale testing, experiments were conducted using thermogravimetric analyser (TGA) together with FTIR in nitrogen at 5, 10 and $20{ }^{\circ} \mathrm{C} / \mathrm{min}$ to determine the thermal stability. For meso-scale testing, experiments were carried out using a cone calorimeter with sample dimensions $100 \times 100 \mathrm{~mm}$ at five different heat fluxes $(30,40$, 50,60 and $70 \mathrm{~kW} / \mathrm{m}^{2}$ ). Relative hazard classification of the fire performance of the current composites has also been compared with other materials using parameters obtained elsewhere [30]. Finally, the effective ignition, thermal and pyrolysis properties obtained from the ignition experiments were used in a numerical model [20] to predict the time to ignition, subsequent mass loss rate and back surface temperatures for all heat fluxes and sample thickness sizes.

\section{RESULTS AND DISCUSSION}

\subsection{Materials}

In the present study, two samples of the same composite at two thicknesses were examined as shown Table 1 denoted as C21 (thickness $2.1 \mathrm{~mm}$ ) and C42 (thickness $4.2 \mathrm{~mm}$ ).

The specimens were supplied as a composite of carbon fibers in an epoxy resin. According to its manufacturer, the composites contain Bisphenol F Epoxy and Tryglycidyl-P-Aminophenol as the resin having with a percentage around $30 \%$ by weight. The density is approximately $1.48 \pm 2 \% \mathrm{~g} / \mathrm{cm}^{3}$. The exact composition is proprietary. 


\subsection{Microscale - TGA-FTIR Analyzer Results}

To characterize the nano-scale behavior, TGA experiments in nitrogen were carried out in a Mettler Toledo TGA, with samples having mass of $12 \pm 1 \mathrm{mg}$, and at three heating rates 5,10 and $20^{\circ} \mathrm{C} / \mathrm{min}$ over a temperature range from ambient temperature $20^{\circ} \mathrm{C}$ to $800^{\circ} \mathrm{C}$. TGA samples in the form of powder were ground using a mechanical grinder. A high resolution digital scale was used to ensure that the same sample mass $(12 \mathrm{mg})$ was used for all tests.

The TGA furnace and the balance were flushed with nitrogen at a flow rate of $50 \mathrm{ml} / \mathrm{min}$ and $100 \mathrm{ml} / \mathrm{min}$ respectively. The gaseous emissions released during the experiments were analyzed with a FTIR spectrometer (Thermo-Nicolet 670) placed at the outlet exhaust of the TGA apparatus. Infrared spectra were recorded in the spectral range of $4000-650 \mathrm{~cm}^{-1}$ with a $0.5 \mathrm{~cm}^{-1}$ resolution and 16 scans. The analysis of multi-component spectra is carried out in two steps. The first step is the calibration or training step based on spectra obtained from standard gases of interest. During the second step, the absorption intensity of the products released is determined.

Fig. 1a shows the mass loss curves versus temperature for the epoxy resin carbon fiber materials at three different heating rates 5,10 and $20^{\circ} \mathrm{C} / \mathrm{min}$ where the results indicate that an increase in the heating rate leads to an increase in the induction temperature. Such shifts towards a higher temperature as the heating rate increases occur owing to the kinetics of degradation in the solid [20]. The thermal decomposition mainly occurs between 300 and $500^{\circ} \mathrm{C}$. At $500^{\circ} \mathrm{C}$, the mass loss is about $23 \%$ of the initial mass. It seems that about $7 \%$ of resin remains in the solid phase as char if we consider that the initial content of the resin is $30 \%$ by mass.

Fig. 1b shows the mass loss rate (MLR) curves for the epoxy resin fiber carbon materials at three different heating rates 5,10 and $20^{\circ} \mathrm{C} / \mathrm{min}$. Notice that the evolution of the curves is quite similar regardless of the heating rate studied, with one main peak of MLR. Indeed the temperature corresponding to the peak of the MLR increases slightly with the heating rate [21].

By using the measurements at different heating rates, the activation energy and preexponential factor $\mathrm{A}\left(\mathrm{s}^{-1}\right)$ in the Arrhenius expression describing the reaction can be determined following the ASTM E698 method [22]. For an assumed one-step first order 
reaction the activation energy is $149 \mathrm{~kJ} / \mathrm{mol}$ and $\log _{10}(\mathrm{~A})$ is 21.4 . The mass loss rates calculated using the deduced activation energy and pre-exponential factor are shown in Fig. $1 \mathrm{~b}$ to be in good agreement with the experimental data. It is worth mentioning that Chen and Yeh [23] studied the degradation of a pure epoxy resin and found the activation energy for epoxy resin is $172.92 \mathrm{~kJ} / \mathrm{mol}$, and the pre-exponential factor $\log _{10}(\mathrm{~A})$ is 16.51 with an order of reaction of 0.4 . The deviation between our results and these in [23] may be due to the different order of reaction, to the presence of carbon fiber in the composite tested in this work or to the use of different additives materials.

The gas emissions released during the TGA experiments were detected using FTIR. Figure 3 presents the FTIR spectra of the gaseous emissions at three different times $(15,20$ and 25 min). The results at other heating rates are similar. As can be shown, after $15 \mathrm{~min}$, some light hydrocarbons were detected, the carbon dioxide was detected after 20min and finally after 25 min, near the end of pyrolysis, the absorbance was small with the gases corresponding to nitrogen oxides and nitrous oxide. Moreover Fig. 3d presents the gaseous emissions intensity as a function of temperature for the major gases $\left(\mathrm{CO}_{2}, \mathrm{CO}\right.$ and water vapour), while all the gaseous emissions and their temperature range are reported in Table 2.

As can be seen from Table 2, water from the composite is released in two regions: the first one (moisture contained in the sample) was in a range of temperature from the room temperature to less than $100^{\circ} \mathrm{C}$. The second one was between 180 and $250^{\circ} \mathrm{C}$, corresponding to the thermal degradation process of the material with a maximal value at $200^{\circ} \mathrm{C}$. Carbon monoxide was also detected between 230 and $450^{\circ} \mathrm{C}$ with a maximal value at $300^{\circ} \mathrm{C}$. Nitrous oxide was observed between 250 and $430^{\circ} \mathrm{C}$ with a maximal value at around $400^{\circ} \mathrm{C}$. Carbon dioxide emissions have one peak $\left(380-430^{\circ}\right)$ with a maximal value at $410^{\circ} \mathrm{C}$. The gaseous emissions detected in this work are similar to those reported in [24], which investigated the pyrolysis of pure epoxy resin and corresponding high-performance carbon fiber-reinforced composites, but the corresponding temperature ranges are different, probably due to the presence of fire retardant or the effect of presence of different additive materials in the both cases.

The combined FTIR/TGA analysis is useful in understanding the pyrolysis of a material because it identifies the gases evolved at different stages of pyrolysis. These gases are directly linked to the flammability and toxicity of a material burning in a real situation. As shown in 
the table 2 the major flammable compounds released around $350^{\circ} \mathrm{C}$, thus we expect that the ignition temperature will be near this value.

\subsection{Meso scale- Cone Calorimeter Results}

\subsubsection{Ignition Times}

The composite samples of two thicknesses were tested at five different heat fluxes 30, 40, 50, 60 and $70 \mathrm{~kW} / \mathrm{m}^{2}$. The operating principles of the oxygen consumption in the cone calorimeter method are presented in [2]. The size of the sample is $100 \mathrm{~mm} \times 100 \mathrm{~mm}$ and the thickness is $4.2 \mathrm{~mm}$ and $2.1 \mathrm{~mm}$. In this work, the tests were conducted using a sample holder used in [25] in order to minimize the conduction heat loss from the sample. Figure 3 presents the sample holder. Cotronics paper is used for insulation of the sample holder. It is worth noting that during experiments a layer of aluminum sheet is placed between the sample and the insulating materials to prevent the melted polymer to soak into the insulation. As this aluminum sheet is very thin, it only absorbs a very small amount of heat. Note that the exhaust hood air flow rate was 24 1/s. The samples are tested in horizontal position and ignited by a spark igniter [26-29]. For each experimental condition, three (3) experiments have been done in order to confirm the repeatability of the results.

It was observed that a few seconds before piloted ignition, smoke is released and its intensity increases until ignition occurs. The smoke is emitted from the top and on the sides of the sample. Piloted ignition seems to start at the edges of the sample and then expands to the whole exposed area. The average of ignition times is rounded to next whole number and presented in Table 3, together with an empirical comparison of their ratio and their difference. The ignition times for C21 (2.1 mm thick) are lower than those for C42 (4.2 mm thick) because the thickness of the thinner material (compared to the thicker material) is much less than the thermal thickness corresponding to the imposed heat fluxes.

\subsubsection{Heat Release Rate and Heat of Combustion}

After ignition and an initial increase of HRR, the heat release rate decreases and then increases again as shown in Fig. 4. It was observed that carbon fibers sometimes were delaminated from the sample.

As can be seen in Fig. 4, the intensity of the first peak decreases slightly as the thickness increases. This peak is attributed to the thermal decomposition of a thin surface layer of the 
composite which is shown in Fig. 10, by comparison with mass loss rate, to have a higher heat of combustion than the bulk of the composite. Subsequently, the epoxy resin starts pyrolysing and a carbon fiber layer forms which thermally shields the still unpyrolysed composite. It is interesting to note that the second peak of the HRR, which is due to the backside effect when the heat has reached the backside of the sample, is almost the same for the two thicknesses. If the samples were well insulated, one would expect that this peak HRR be higher for thinner samples. This result indicates higher heat losses to the insulation in the case of C21 having thickness of $2.1 \mathrm{~mm}$.

Figure 5 presents the total heat release (THR) as well as the average heat of combustion for the composite material. The THR for C42 is approximately on the average twice that for C21 whereas the effective heats of combustion are similar indicating that the combustion of the pyrolysing gases is similar for both formulations. Notice that the mass of epoxy in the thick composite is approximately twice the mass of epoxy in the thin composite.

\subsection{3. $\mathrm{CO}_{2}, \mathrm{CO}$ and smoke Yields Used for Relative Classification of Toxicity}

Typically, fire fatalities are reported as resulting from the inhalation of smoke and toxic gases. Using the exhaust flow rate, the gaseous concentration and extinction measurements, the mass flow rate $(\mathrm{g} / \mathrm{s})$ of the exhaust specie are calculated whereas their yields $(\mathrm{g} / \mathrm{g})$ can be determined as the ratio between the mass production of the specie and the total mass loss of the composite material. The smoke calculations are done according to Lambert Beers law [25].

The smoke, the carbon monoxide and carbon dioxide yields are given in Table 4 based on measurements at both thicknesses. This data will be used next to estimate the Toxicity Parameter [30-31].

Based on the TGA and cone calorimeter results, it is possible to deduce the main parameters that can be used for characterising the fire performance of materials, namely Fire Growth Parameter, Smoke Parameter, Toxicity parameter, Mass residue and Heat release rate for thermally thin materials [30].

The fire growth parameter is determined by the following relation, based on the measurement performed in the Cone Calorimeter at an external heat flux of $50 \mathrm{~kW} / \mathrm{m}^{2}$. 


$$
\text { Fire Growth Parameter }=\frac{P H R R^{2}}{t_{i g n}}
$$

Where $\mathrm{PHRR}^{2}$ is the square of the maximum heat release rate per unit area and $t_{\text {ign }}$ is the ignition time.

The smoke parameter in Fig. 6a is the smoke yield, Ys and in Fig. $6 \mathrm{~b}$ is the modified smoke yield divided by the effective heat of combustion as measured in the Cone Calorimeter.

$$
\text { Smoke parameter }=\mathrm{Ys} / \Delta \mathrm{H}_{\mathrm{c}}(\mathrm{g} / \mathrm{kJ})
$$

The toxicity parameter is defined from the ratio of the effective heat of combustion of the composite to that of the neat epoxy resin in the following way:

$$
\text { Toxicity parameter }=1-\frac{\Delta H_{c, \text { resin_composite }}}{\Delta H_{c, \text { neat_resin }}}
$$

It represents the inefficiency of combustion which is related to the incompleteness of combustion of the basic resin.

The Mass residue describes how much of the initial material is left behind as residue after combustion. This is not significant for fire spread and growth but it can provide the amount of total fuel load in a fully developed fire. This quantity can be measured in the Cone calorimeter or in TGA in Nitrogen with experiments showing that these quantities so measured have close values [30].

Finally, the heat release rate for thermally thin materials can be characterized by using the measurements in TGA, where the maximum mass loss rate in Nitrogen (appropriately normalized by the initial mass and heating rate) is multiplied by the heat of combustion measured in the Cone Calorimeter. For thermally thin conditions (e.g. a thin sheet of the material), the material pyrolyses as the mg samples do in the TGA in Nitrogen, where thermally thin conditions (i.e. uniform heating) prevail. Therefore, we can characterize the heat release rate under thermally thin burning conditions by the maximum pyrolysis rate in the TGA multiplied by the effective heat of combustion in the Cone Calorimeter normalized by the initial mass (proportional to the thickness of the material) and divided by the heating 
rate in the TGA, because the maximum pyrolysis rate in the TGA is nearly proportional to the heating rate. It can be determined by the following relation:

$$
\text { Heat release parameter for thermally thin conditions }=\frac{\Delta H_{c}}{\beta * m_{0}}\left(\frac{d m}{d t}\right)_{\max }
$$

Where $\beta$ is the heating rate, $m_{0}$ is the initial mass, $(\mathrm{dm} / \mathrm{dt})_{\max }$ is the maximum of mass loss rate from TGA data and the $\Delta \mathrm{H}_{\mathrm{c}}$ is the heat of combustion from cone calorimeter data [30].

Figure 6 shows a comparison of the fire growth against smoke parameter between the current formulations and other materials tested in the European project (Aircraft Fire- FP7-2010265612) [30], including PMMA, carbon fiber reinforced PEEK (Polyether ether ketone), carpet used in the modern aircraft, Phenolic composite and thermo-acoustic insulation. Figure 6 shows that the current composites have much lower fire growth parameter than PMMA but higher than that of carbon fiber reinforced PEEK and phenolic composite. Both formulations are similar in terms of the smoke parameter, but $\mathrm{C} 42$ has a slightly lower fire growth parameter compared to $\mathrm{C} 21$ since both have similar PHRRs but $\mathrm{C} 42$ has a higher ignition time.

\subsection{Flammability properties and prediction of mass loss rate}

\subsubsection{Effective Thermal and Ignition Properties}

The effective ignition properties (considered independent of temperature) of a thermally intermediate material can be determined by plotting the time-to-ignition as a function of the heat flux for thermally thick and thin conditions for C42 as shown in Fig. 6 using the methodology in [30-31] which is briefly described next.

The results are reported in Table 6 together with similar properties from the literature [31-33]. Notice that the left ordinate in Fig. 7 is the inverse of the square root of the ignition time divided by a function F1 depending on the thermal diffusivity and thickness of the material [30-31]. This ordinate is appropriate if the solid behaves as thermally thick for which case the ignition data should lie on a straight line. The right ordinate in Fig. 7 is the inverse of the ignition time $1 / \mathrm{t}_{\text {ign }}$ divided by a function $\mathrm{F} 2$ depending on the thermal diffusivity and thickness of the material [30-31]. This ordinate is appropriate if the solid behaves as thermally thin for which case the ignition data should lie on a straight line. By matching the slopes of 
these two lines, the value of the thermal diffusivity can be determined as well as the critical heat flux and the thermal inertial parameter $(\mathrm{k} \rho \mathrm{c})$.

Then, using the measured density of the material, $\mathrm{k}$ (conductivity) and $\mathrm{c}_{\mathrm{p}}$ (specific heat) can be determined [30-31]. The ignition temperature is deduced from critical heat flux. The effective flammability properties deduced here are within the range of properties reported in the literature as shown in Table 6. Notice that the ignition temperature in [32] is very low in relation to critical heat flux as it was measured using thermocouples which may have moved from the surface because the epoxy melts at higher temperatures before ignition. It should be noted again here that even though the conductivity and specific heat change with temperature, those determined from the ignition tests are effective (average) values.

As can be seen by comparison of the results in Table 6 and Figs 1 and 2, TGA /FTIR measurements confirm that the ignition temperature deduced from cone calorimeter is nearly equal with the temperature where flammable gases are released, and when also the maximum MLR occurs.

\subsubsection{Mass loss rate predictions using the Heat Flux Ratio}

The authors have previously developed a numerical model for PA6 nanocomposite [20, 34] and further validated against other polymer nanocomposites and flaxboard with intumescent coatings [35].The fundamental parameter used to characterize the effect of the charring layer formed on top of the unpyrolysed material is a heat flux ratio [20, 34-35]:

$$
\operatorname{Flux}_{\text {ratio }}(t)=\frac{\dot{q}_{\text {net_o }}^{\prime \prime}}{\dot{q}_{\text {net }}^{\prime \prime}(t)}
$$

Where $\dot{q}_{\text {net_o }}^{\prime \prime}$ is the net incoming heat flux on the surface for the case when there is no surface layer and $\dot{q}_{n e t}^{\prime \prime}(t)$ is the actual heat flux at the interface of the surface (nanoparticle) and unpyrolysed depth. The heat flux, $\dot{q}_{n e t}^{\prime \prime}{ }_{0}$, can be determined based on the energy balance on the surface where $\dot{q}_{n e t}^{\prime \prime}(t)$ is calculated using a $1 \mathrm{~d}$ heat transfer numerical model with the pyrolysed depth calculated from the experimental mass loss rate, sample density and surface area [20, 34-35].

The key assumption of the model is that the heat transfer in the cone calorimeter is one dimensional. An adiabatic condition was used at the back of the sample for calculating the 
backside temperature, because in the experiments the back of the sample was insulated with very low conductivity Cotronics.

In the present study, we apply the same methodology for the carbon fiber reinforced Epoxy because of its similar burning characteristics as polymer nanocomposites or typical charring materials. From the experimental mass loss rate and using the effective ignition properties deduced earlier, the heat flux ratio, namely the net heat flux on the surface for the case when there is no surface shielding CF layer to the actual heat flux at the interface between the surface layer and the unpyrolysed material, can be calculated as a function of the pyrolysis depth, i.e., the depth of the material that has pyrolysed [19-20, 31-35]. Note that due to the large fluctuations in the raw mass loss rate data, the mass loss rate data used in the calculations were calculated using the raw heat release rate divided by the average heat of combustion $(20 \mathrm{~kJ} / \mathrm{g})$ for $\mathrm{C} 42(4.1 \mathrm{~mm})$. Figure 8 presents the deduced heat flux ratio (as done in references 19, 31-33) as a function of the pyrolysis depth at different heat fluxes. Although there are some fluctuations especially at the start of pyrolysis, the data seems to suggest that the heat flux ratio increases linearly with the pyrolysis depth $(\delta)$ as expected from a typical charring materials [30-31, 34-35]. A best fit of the data shows that the following relation is valid Flux $x_{\text {ratio }}=1+4500 \delta_{\text {pyro }}$ independent of the heat flux. Note that $\delta_{\text {pyro }}$ is the pyrolysis depth, i.e., the depth of the material that has pyrolysed (m). Notice that the pyrolysis depth was determined by the mass loss divided by the density and by the sample area. Note that this relation is independent of the initial thickness of the material [19-20]. In fact, the data related the C42 has been used in this step because the accuracy of pyrolysis depth is less for the thinner composite than the thicker composite.

\subsubsection{Predicted mass loss rate}

The relation between the heat flux ratio and pyrolysis depth in Fig. 8, together with the ignition and pyrolysis (using the TGA data Arrhenius expression or a thermal pyrolysis model) properties can be used to predict the mass loss rate [19, 30-31, 34-35] as shown in Fig. 9, for different imposed heat fluxes in the cone calorimeter.

A comparison between the prediction and measured MLRs is shown in Fig. 10. Note that for comparison purpose, the raw MLRs and the ones deduced from the HRRs are both included. The model data presented here start from the ignition time, as shown in Fig.9 and 10, so that the ignition times in Fig.10 are about 75, 50, 35 and $25 \mathrm{~s}$ at 40, 50, 60 and $70 \mathrm{KW} / \mathrm{m}^{2}$ 
respectively. The predicted times to ignition and peak values of the MLR are in general good agreement with the experimental data as shown in Fig. 10 and table 3.

The major difference in Fig. 10 is that the experimental MLRs eventually become zero whereas the predicted MLRs failed to drop to zero, because at that point all resins has been consumed. This is probably due to underestimation of the mass of resin.

Nonetheless, these results show that the concept of heat flux ratio can be used to explain and more importantly to predict the burning behaviors of a material forming a protecting layer (e.g. carbon fiber) with unknown and difficult to determine thermal properties such as the carbon fiber composite tested here. Notice that the mass loss rate data were calculated from the HRR data divided by the heat of combustion of $20 \mathrm{~kJ} / \mathrm{g}$.

We note in Fig. 10 that the calculated mass loss rate from the HRR using a constant heat of combustion is much higher than the experimental mass loss rate at the first peak after ignition of the surface layer. We suggest that this result demonstrates that the surface layer should consist of a different component having a higher heat of combustion than the bulk of the material.

In order to examine the effect of thickness, calculations were performed for other thicknesses, i.e., 2, 4, 6 and $8 \mathrm{~mm}$ at 50kW/m 2 as shown in Fig. 11, with the model developed here. Notice that the experimental data of mass loss for the thinner composite was very noisy due to the small initial mass compared to the sample holder mass and to the warping of the composite during these tests. As can be seen in Fig. 11, the peak of mass loss rate is around $0.28 \mathrm{~g} / \mathrm{s}$ and this value is double of mass loss rate deduced from the peak of heat release rate ( shown in Fig. 4 -C21 ) divided by the heat of combustion (in our case $20 \mathrm{~kJ} / \mathrm{g}$ ) .

At $2 \mathrm{~mm}$, the material behaves like a thermally thin material with a much higher peak MLR. With an increase in the thickness, the peak MLR decreases significantly also having a shift in the time required to reach the peak MLR.

In Fig. 12, the predicted backside temperature is compared to the measurements at different heat fluxes. The experimental backside temperature measurement has been conducted in two different laboratories in order to verify the repeatability of the measurement. The data from the repeated tests are similar when time is less than $130 \mathrm{sec}$, after which a discrepancy between the two measurements is noted. (The blue line represents the back surface 
temperature data obtained in another laboratory (Institute P'-CNRS France) denote as ExLab).

At the heating-up stage, i.e., before pyrolysis starts, the predictions agree well with the experimental data, indicating the validity of the effective properties deduced from ignition times at different heat fluxes. After ignition, the predictions start to deviate from the experimental data with a maximum difference of $80^{\circ} \mathrm{C}$. A possible reason could be the use of the ignition temperature concept in the model, namely, pyrolysis/ignition only occurs when the temperature reaches the ignition temperature and remain the same for the whole duration pyrolysis. This assumption is only approximate as it is known that pyrolysis typically takes place in a temperature range albeit small. Another possible reason is that the model does not take into account conduction heat losses, which could be significant towards the end of the test when the thickness of the material is small. The difference is however reduced as the heat flux increases.

\section{CONCLUSIONS}

The present work investigates the thermal degradation and burning behaviors of a Carbon Fiber composite material used in the aviation industry (carbon-fiber reinforced Epoxy) using TGA/FTIR and cone calorimeter measurements for two thicknesses (2.1 and $4.2 \mathrm{~mm})$ of the material. Furthermore, a numerical pyrolysis model incorporating the ignition and pyrolysis properties deduced from the cone calorimeter experiments was used to predict the ignition times, the back surface temperature and mass loss rate in the cone calorimeter at different heat fluxes. The main conclusions of this work are:

- The TGA/FTIR experiments show that a) the composite has no thermal degradation before $300^{\circ} \mathrm{C}$ and $\mathrm{b}$ ) the material degrades owing to one-step reaction.

- The sample thickness has an important effect on the time to ignition as the $2.1 \mathrm{~mm}$ sample ignites much earlier than the $4.2 \mathrm{~mm}$ sample as measured experimentally and predicted by the present pyrolysis model.

- The HRR curves show two peaks, the first due to the pyrolysis of a thin surface layer of the composite (see discussion on Fig.10) and the second is affected by the back side thermal insulation effect. We note that after the first thin layer burns, the epoxy resin starts pyrolysing and a carbon fiber layer forms which thermally shields the still un-pyrolysed 
composite leading to the formation of the second heat release peak. The heat of combustion and smoke yields are similar for the materials of two different thicknesses.

- Relative hazard classification of the fire performance of the current composites has also been compared with other materials (Fig. 6) using parameters obtained elsewhere [30].

- The thermal parameters obtained from the ignition and burning tests in the cone calorimeter were used in a pyrolysis model for the heat fluxes (Fig.8) to predict the time to ignition and mass loss rate in good agreement with the experimental data for the $4.2 \mathrm{~mm}$ thick sample but providing higher maximum mass loss rates for the $2.1 \mathrm{~mm}$ sample probably because heat losses from the back surface to insulation are neglected in the model.

- Finally, the same pyrolysis model provides good prediction of the back surface temperature of the composite as shown in Fig. 12.

\section{Acknowledgements}

The authors acknowledge the EU for financially supporting the Aircraft-fire project under

Grant No 265612.

\section{References}

1. Mouritz, A., Feih, S., Kandare, E., Mathys, Z., Gibson, G., Des Jardin, P., Case, W., Lattimer, B., "Review of fire structural modelling of polymer composites", Composites Part A: Applied Science and Manufacturing. 40: 1800-1814 (2009).

2. Babrauskas, V., "Development of the cone calorimeter - a bench-scale heat release rate apparatus based on oxygen consumption”, Fire and Materials. 8: 81-95 (1984).

3. Wilkie, C., "TGA-FTIR an extremely useful technique for studying polymer degradation", Polymer Degradation and Stability. 66: 301-306 (1999).

4. Kotresh, T., Indushekar, R., Subbulakshmi, M,. Vijayalakshmi, S., Krishna Prasad, S., Gaurav, K., "Evaluation of foam/single and multiple layer Nomex fabric combinations in the cone calorimeter", Polymer Testing. 24: 607-612 (2005).

5. Tewarson, A., Macaione, P., "Polymers and composites - an examination of fire spread and generation of heat and fire products", Journal of Fire Sciences. 11: 421-41 (1993).

6. Scudamore, M.J., Fire performance studies on glass-reinforced plastic laminates, Fire and Materials. 18: 313-25 (1994). 
7. Brown, J.R., Fawell, P.D., Mathys, Z., "Fire-hazard assessment of extended-chain polyethylene and aramid composites by cone calorimeter", Fire and Materials. 18: 16772 (1994).

8. Egglestone, G.T., Turley, D.M., "Flammability of GRP for use in ship superstructures", Fire and Materials. 18: 255-60 (1994).

9. Hshieh, F.Y., Beeson, H.D., "Flammability testing of flame-retarded epoxy composites and phenolic composites", Fire and Materials. 21: 41-49 (1997).

10. Grenier, A.T., Dembsey, N.A., Barnett, J.B., "Fire characteristics of cored composite materials for marine use", Fire Safety Journal. 30: 137-59 (1998).

11. Mouritz, A.P., "Review of smoke toxicity of fiber-polymer composites used in aircraft", Journal of Aircraft. 46: 737-45 (2009).

12. Fanucci, J.P., "Thermal response of radiantly heated kevlar and graphite/epoxy composites", Journal of Composite Materials. 21: 129-39 (1987).

13. Ott, H.J., "Thermal conductivity of composite materials", Plastics and Rubber Processing and Applications. 1: 9-24 (1981).

14. Gu, P., Asaro, R.J., "Distortion of polymer matrix composite panels under transverse thermal gradients", Composite Structures. 82: 413-21 (2008).

15. Gu, P., Asaro, R.J., "Wrinkling of sandwich polymer matrix composite panels under transverse thermal gradients", Fire Safe Journal. 43: 151-60 (2008).

16. Chang, C.I., "Thermal effects on polymer composite structures", Theoretical and Applied Fracture Mechanics. 6: 113-20 (1986).

17. Pering, G.A., Farrell, P.V., Springer, G.S., "Degradation of tensile and shear properties of composites exposed to fire or high temperature". Journal of Composite Materials. 14: 5466 (1989).

18. Lyon, R.E., “Advanced fire safe aircraft materials research programme”. Technical report DOT/FAA/CT-94/60 (1994).

19. Hagen, M., Hereid, J., Delichatsios, M., Zhang, J., Bakirtzis, D., "Flammability assessment of fire-retarded Nordic Spruce wood using thermo-gravimetric analyses and cone calorimetry”, Fire Safety Journal. 44: 1053-1066 (2009).

20. Zhang, J., Delichatsios, M., Bourbigot, S., "Experimental and numerical study of the effects of nanoparticles on pyrolysis of a polyamide 6 (PA6) nanocomposite in the cone calorimeter", Combustion and Flame. 156: 2056-2062 (2009).

21. Zhang, J., Delichatsios, M., "TGA Maximum Heat Release Rate and Mass Loss Rate and Comparison with the Cone Calorimeter", Fire Safety Science. 10: 1333-1346 (2011). 
22. ASTM E698-05., "Standard test method for Arrhenius kinetic constants for thermally unstable materials". doi:10.1520/E0698-05.

23. Chen, K., Yeh, R., "Pyrolysis kinetics of epoxy resin in a nitrogen", Journal of Hazardous Materials. 49: 105-113 (1996).

24. Schartel, B., et All., "Pyrolysis of epoxy resins and fire behavior of epoxy resin composites flame-retarded with 9,10-dihydro-9-oxa-10-phosphaphenanthrene-10-oxide additives", Journal of Applied Polymer Science. 104: 2260-2269 (2007).

25. Delichatsios, M., Paroz, B., Bhargava, A., "Flammability properties for charring materials", Fire Safety Journal. 38: 219-228 (2003).

26. ISO 5660., Fire Test, Reaction to Fire, Rate of Heat Release from Building Products, International Standards Organization, Geneva (1993).

27. Kuang-Chung, T., Drysdale, D., "Using cone calorimeter data for the prediction of fire hazard", Fire Safety Journal. 37: 697-706 (2002).

28. Fateh, T., Rogaume, T., Richard, F., "Multi-scale modeling of the thermal decomposition of fire retardant plywood", Fire Safety Journal. 64: 36-47 (2014).

29. Fateh, T., Rogaume, T., Luche, J., Richard, F., Jabouille, F., "Characterization of the thermal decomposition of two kinds of plywood with a cone calorimeter - FTIR apparatus", Journal of Analytical and Applied Pyrolysis. 107: 87-100 (2014).

30. Suzanne, M., Ukleja, S., Delichatsios, M., Zhang, J., Karlsson,B., "Fundamental flame spread and toxicity evaluation of fire retarded polymers", 11th International Symposium on Fire Safety Science, Canterbury, New Zealand, (2014).

31. Delichatsios, M., "Piloted ignition times, critical heat fluxes and mass loss rates at reduced oxygen atmospheres", Fire safety Journal. 40: 197-212 (2005).

32. Quang Dao, D., Luche, J., Richard, F., Rogaume, T., Bourhy-Weber, C., Ruban, S., "Determination of characteristic parameters for the thermal decomposition of epoxy resin/carbon fibre composites in cone calorimeter", International Journal of Hydrogen Energy. 38: 8167-8178 (2013).

33. Tewarson, A., "Generation of heat and gaseous, liquid, and solid products in fires". In: SFPE Handbook of Fire Protection engineering. Chapters 3: 3-109 (2008).

34. Zhang, J., Delichatsios, M., "Further Validation of a Numerical Model for Prediction of Pyrolysis of Polymer Nanocomposites in the Cone Calorimeter", Fire Technology. 46: 307-319 (2010). 
35. Zhang, J., Delichatsios, M., McKee, M., Ukleja, S., "Experimental and numerical study of burning behaviors of flaxboard with intumescent coating and nanoparticles in the cone calorimeter and single burning item tests", Fire and Materials, 36: 554-564 (2012). 
Table 1. Details of composites tested.

\begin{tabular}{c|c|c}
\hline Sample specification & $\mathbf{C 4 2}$ & C21 \\
\hline Fiber & Carbon & Carbon \\
\hline Matrix & Epoxy & Epoxy \\
\hline Fiber barrier & Single laminate & Single laminate \\
\hline Layup orientation & {$\left[-135 / 90 / 45 / 0^{\circ}\right]$} & {$\left[-135 / 90 / 45 / 0^{\circ}\right]$} \\
\hline Thickness & $4.2 \mathrm{~mm}$ & $2.1 \mathrm{~mm}$ \\
\hline
\end{tabular}


Table 2. Details of gaseous emissions detected during the TGA experiments.

\begin{tabular}{c|c|c|c|c|c|c|c|c|c}
\hline \multirow{2}{*}{ Gas } & \multicolumn{3}{|c|}{ First released } & \multicolumn{2}{c|}{ Second released } & \multicolumn{2}{c}{ Third released } \\
\hline & Start & End & max & Start & End & max & Start & End & Max \\
\hline $\mathrm{H}_{2} \mathrm{O}\left(3775 \mathrm{~cm}^{-1}\right)$ & $30^{\circ} \mathrm{C}$ & $90^{\circ} \mathrm{C}$ & $30^{\circ} \mathrm{C}$ & $140^{\circ} \mathrm{C}$ & $250^{\circ} \mathrm{C}$ & $200^{\circ} \mathrm{C}$ & & & \\
\hline $\mathrm{CO}\left(2116 \mathrm{~cm}^{-1}\right)$ & $230^{\circ} \mathrm{C}$ & $340^{\circ} \mathrm{C}$ & $300^{\circ} \mathrm{C}$ & $340^{\circ} \mathrm{C}$ & $450^{\circ} \mathrm{C}$ & $370^{\circ} \mathrm{C}$ & & & \\
\hline $\mathrm{CO}_{2}\left(3673 \mathrm{~cm}^{-1}\right)$ & $380^{\circ} \mathrm{C}$ & $430^{\circ} \mathrm{C}$ & $410^{\circ} \mathrm{C}$ & & & & & & \\
\hline $\begin{array}{c}\text { Methanol } \\
\left(1250 \mathrm{~cm}^{-1}\right)\end{array}$ & $450^{\circ} \mathrm{C}$ & End & $600^{\circ} \mathrm{C}$ & & & & & & \\
\hline $\mathrm{N}_{2} \mathrm{O}\left(2205 \mathrm{~cm}^{-1}\right)$ & $250^{\circ} \mathrm{C}$ & $350^{\circ} \mathrm{C}$ & $300^{\circ} \mathrm{C}$ & $360^{\circ} \mathrm{C}$ & $430^{\circ} \mathrm{C}$ & $400^{\circ} \mathrm{C}$ & & & \\
\hline $\begin{array}{c}\text { Ethylene } \\
\left(994 \mathrm{~cm}^{-1}\right)\end{array}$ & $200^{\circ} \mathrm{C}$ & $300^{\circ} \mathrm{C}$ & $280^{\circ} \mathrm{C}$ & $350^{\circ} \mathrm{C}$ & $400^{\circ} \mathrm{C}$ & $370^{\circ} \mathrm{C}$ & $460^{\circ} \mathrm{C}$ & End & $480^{\circ} \mathrm{C}$ \\
\hline $\begin{array}{c}\text { Formaldehyde } \\
\left(1766 \mathrm{~cm}^{-1}\right)\end{array}$ & $220^{\circ} \mathrm{C}$ & $280^{\circ} \mathrm{C}$ & $240^{\circ} \mathrm{C}$ & $340^{\circ} \mathrm{C}$ & $420^{\circ} \mathrm{C}$ & $370^{\circ} \mathrm{C}$ & $510^{\circ} \mathrm{C}$ & End & $540^{\circ} \mathrm{C}$ \\
\hline $\begin{array}{c}\text { Acetaldehyde } \\
\left(1725 \mathrm{~cm}^{-1}\right)\end{array}$ & $250^{\circ} \mathrm{C}$ & $370^{\circ} \mathrm{C}$ & $340^{\circ} \mathrm{C}$ & $470^{\circ} \mathrm{C}$ & End & $520^{\circ} \mathrm{C}$ & & & \\
\hline${\mathrm{HCN}\left(3321 \mathrm{~cm}^{-1}\right)}$ & $180^{\circ} \mathrm{C}$ & $280^{\circ} \mathrm{C}$ & $230^{\circ} \mathrm{C}$ & $350^{\circ} \mathrm{C}$ & $380^{\circ} \mathrm{C}$ & $360^{\circ} \mathrm{C}$ & 410 & End & $550^{\circ} \mathrm{C}$ \\
\hline $\mathrm{NO}_{\left(1820 \mathrm{~cm}^{-1}\right)}$ & $180^{\circ} \mathrm{C}$ & $300^{\circ} \mathrm{C}$ & $250^{\circ} \mathrm{C}$ & $370^{\circ} \mathrm{C}$ & $430^{\circ} \mathrm{C}$ & $420^{\circ} \mathrm{C}$ & $470^{\circ} \mathrm{C}$ & End & $570^{\circ} \mathrm{C}$ \\
\hline $\mathrm{NO}_{2}\left(1611 \mathrm{~cm}^{-1}\right)$ & $200^{\circ} \mathrm{C}$ & $300^{\circ} \mathrm{C}$ & $230^{\circ} \mathrm{C}$ & $380^{\circ} \mathrm{C}$ & $400^{\circ} \mathrm{C}$ & $390^{\circ} \mathrm{C}$ & & & \\
\hline
\end{tabular}


Table 3. Ignition time as function of the heat flux.

\begin{tabular}{|c|c|c|c|c|c|}
\hline Heat Flux $\left(\mathrm{kW} / \mathrm{m}^{2}\right)$ & 30 & 40 & 50 & 60 & 70 \\
\hline $\mathrm{t}_{\mathrm{ig} \_} \mathrm{C} 42(\mathrm{~s})$ & 177 & 72 & 49 & 33 & 25 \\
\hline $\mathrm{t}_{\mathrm{ig} \_} \mathrm{C} 21(\mathrm{~s})$ & 60 & 49 & 30 & 21 & 17 \\
\hline $\mathrm{t}_{\mathrm{ig} \_} \mathrm{C} 42 / \mathrm{t}_{\mathrm{ig} \_} \mathrm{C} 21$ & 2.9 & 1.5 & 1.7 & 1.6 & 1.5 \\
\hline $\mathrm{t}_{\mathrm{ig} \_} \mathrm{C} 42-\mathrm{t}_{\mathrm{ig} \_} \mathrm{C} 21$ & 116.7 & 23.3 & 19.3 & 12 & 8 \\
\hline
\end{tabular}


Table 4. $\mathrm{CO}_{2}$ yield $(\mathrm{g} / \mathrm{g}$ ) for composite materials.

\begin{tabular}{c|c}
\hline Parameter & $(\mathbf{g} / \mathbf{g})$ \\
\hline $\mathrm{CO}_{2}$ yield & $2.3 \pm 34 \%$ \\
\hline CO yield & $0.07 \pm 43 \%$ \\
\hline Smoke yield, Ys & $0.065 \pm 54 \%$ \\
\hline
\end{tabular}


Table 5. Flammability and Toxicity Parameters [30].

\begin{tabular}{c|c|c}
\hline Parameters & $\mathbf{C 4 2}$ & C21 \\
\hline Fire Growth Parameter $\left(\mathrm{kW}^{2} / \mathrm{m}^{4} . \mathrm{s}\right)$ & 1605 & 2754 \\
\hline Smoke Parameter $(\mathrm{g} / \mathrm{kJ})$ & 0.0033 & 0.0033 \\
\hline Toxicity parameter & 0.20 & 0.35 \\
\hline Mass residue from cone calorimeter (\%) & $70 \%$ & $66 \%$ \\
\hline Heat release rate for thermally thin materials $(\mathrm{kJ} / \mathrm{g} . \mathrm{K})$ & 0.073 & 0.060 \\
\hline
\end{tabular}


Table 6. Thermal properties and thermal inertia values.

\begin{tabular}{|c|c|c|c|c|c|c|}
\hline Material & $\mathbf{Q}_{\text {cri }}$ & $\mathbf{T}_{\mathrm{ig}}$ & $\mathbf{k}$ & $\rho$ & $\mathbf{c}_{\mathrm{p}}$ & kpc \\
\hline & $\mathrm{kW} / \mathrm{m}^{2}$ & $\mathrm{~K}$ & $\mathrm{~W} / \mathrm{m} . \mathrm{K}$ & $\mathrm{Kg} / \mathrm{m}$ & $\mathrm{J} / \mathrm{kg} \cdot \mathrm{K}$ & $\mathrm{kW}^{2} / \mathrm{s} . \mathrm{m}^{4} \mathrm{~K}^{2}$ \\
\hline $\begin{array}{l}\text { Composite in } \\
\text { this study }\end{array}$ & 10.2 & 650 & 0.45 & 1480 & 1524.9 & 1.02 \\
\hline $\begin{array}{l}56 \% \text { epoxy } \\
\text { carbon fiber } \\
\text { composite [32] }\end{array}$ & 18 & 513 & - & - & - & 5.07 \\
\hline $\begin{array}{l}59 \% \text { epoxy } \\
\text { carbon fiber } \\
\text { composite[32] }\end{array}$ & 14 & 573 & - & - & - & 2.25 \\
\hline $\begin{array}{l}\text { Epoxy } \\
\text { resin[33] }\end{array}$ & $13-20$ & $\begin{array}{l}648- \\
698\end{array}$ & - & - & - & - \\
\hline $\begin{array}{l}\text { Epoxy }(\mathrm{EP}) / \\
\text { fiber Glass [33] }\end{array}$ & $10-15$ & - & - & - & - & - \\
\hline
\end{tabular}




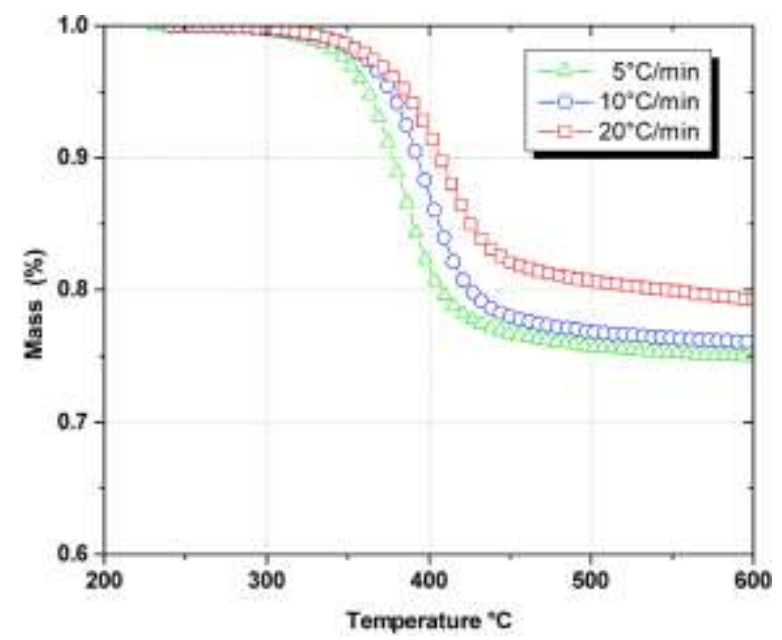

Figure 1a: Mass loss under nitrogen.

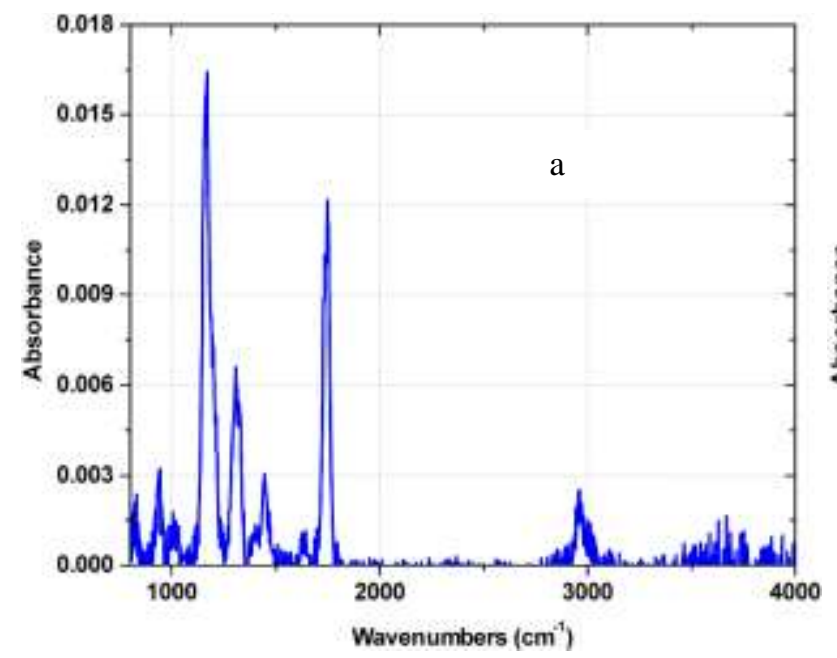

$15 \min \left(300^{\circ} \mathrm{C}\right)$

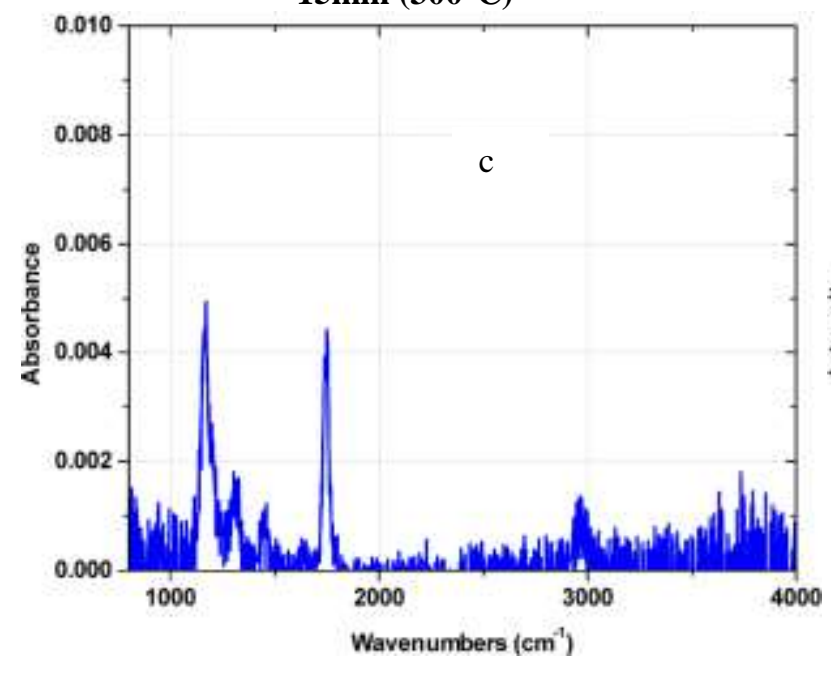

$25 \min \left(500^{\circ} \mathrm{C}\right)$

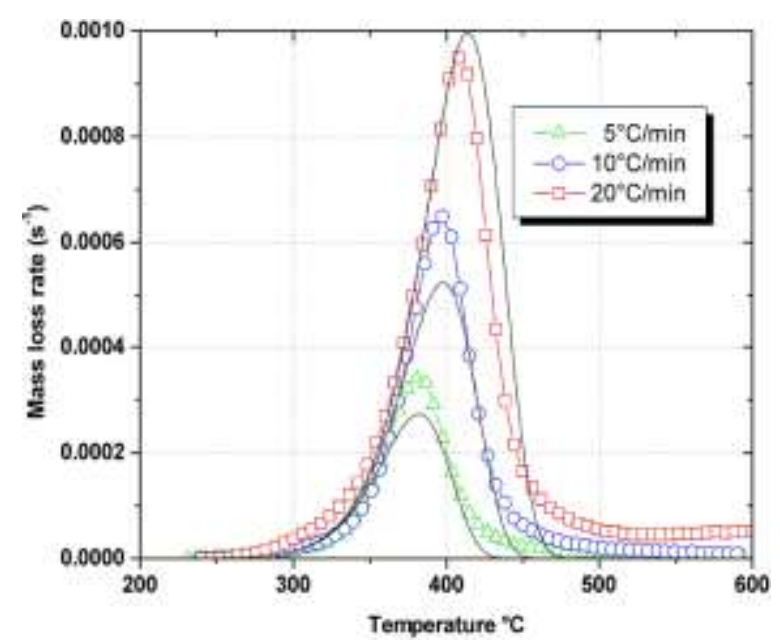

Figure 1b: Mass loss rate under nitrogen.
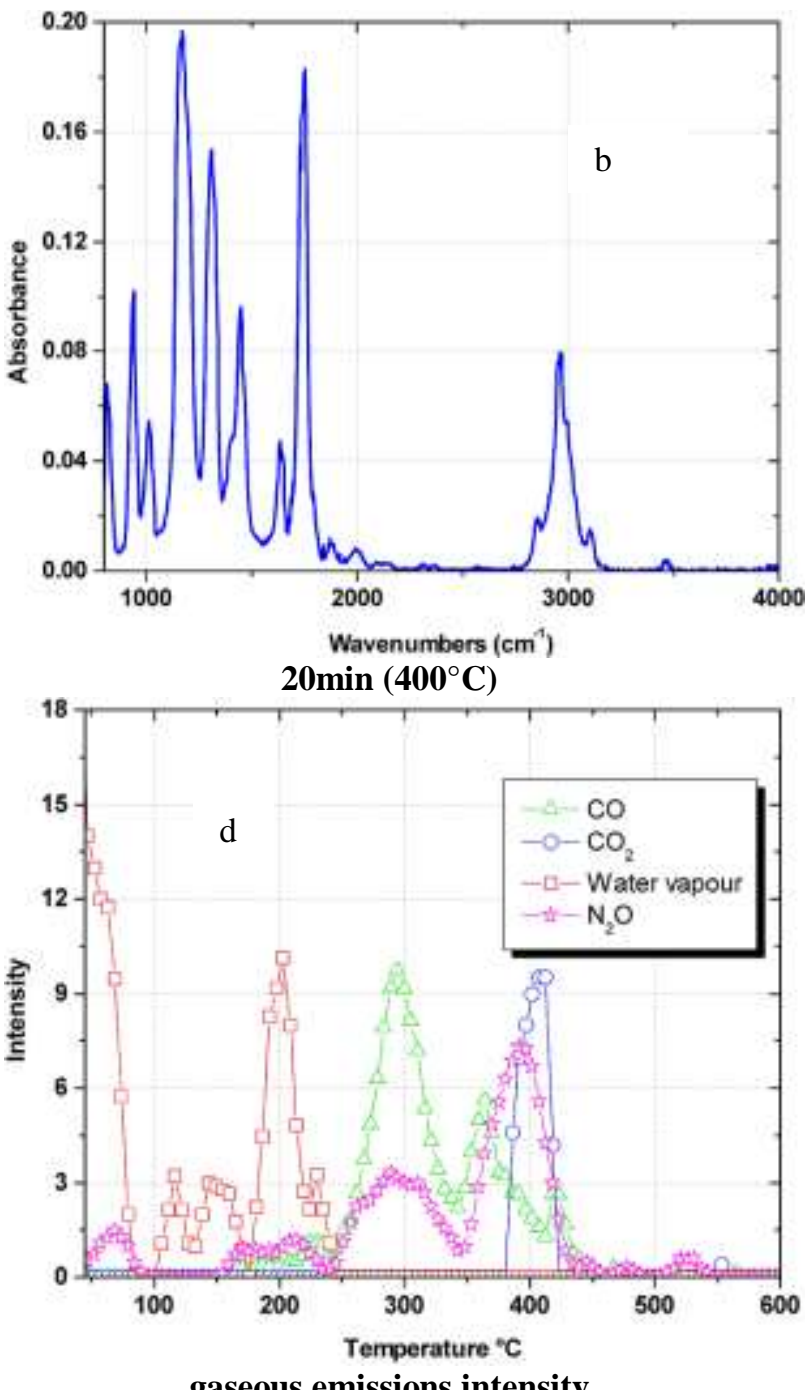

gaseous emissions intensity

Figure 2. FTIR spectra (at 15, 20 and $25 \mathrm{~min}$ ) as well the intensity of gaseous emissions released during the thermal decomposition of the composite materials in $\mathrm{N} 2$ in TGA at $20^{\circ} \mathrm{C} / \mathrm{min}$. 


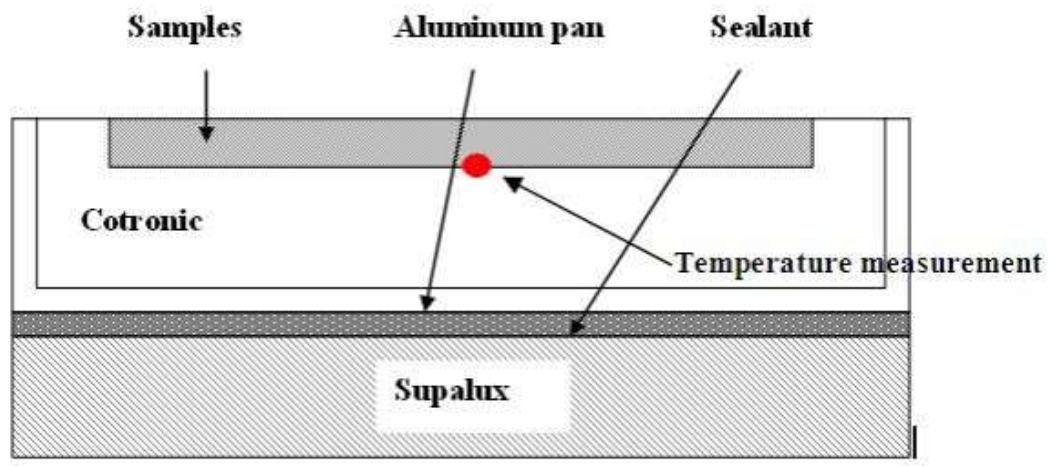

Figure 3. Illustration of the sample holder.
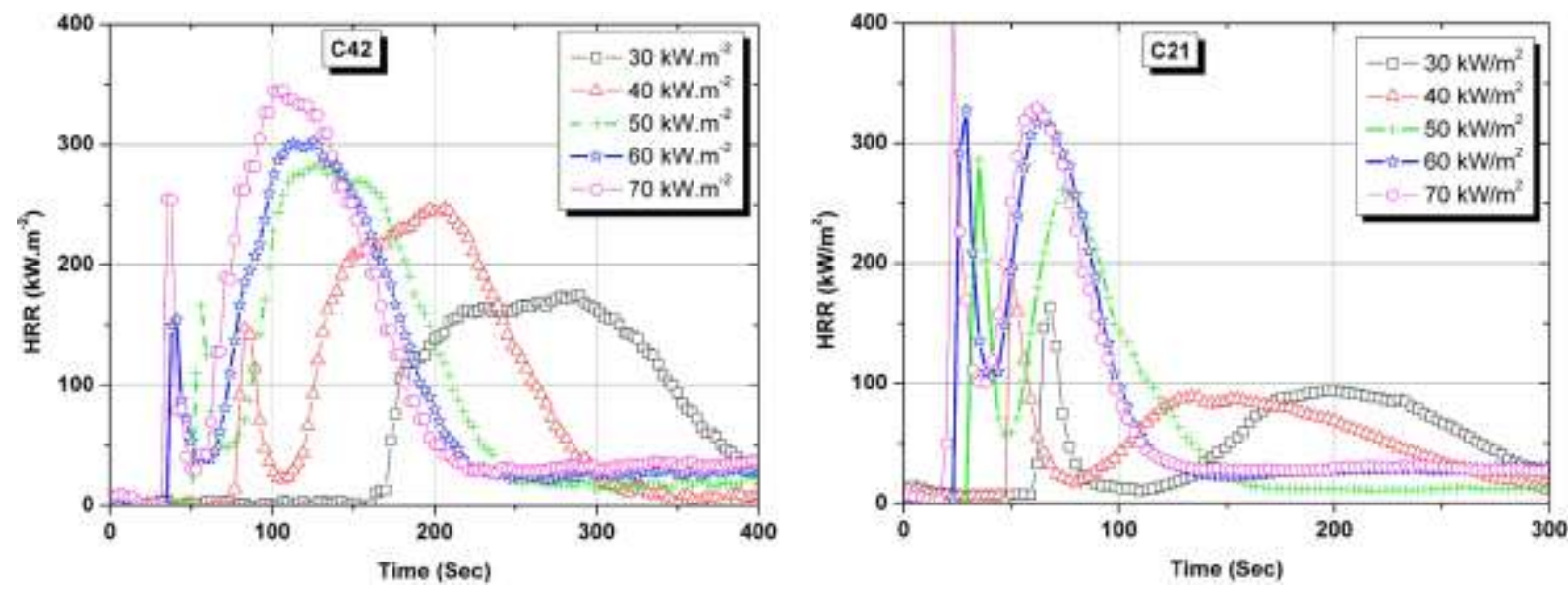

Figure 4. The HRR for carbon-epoxy materials as a function of time for two different thicknesses
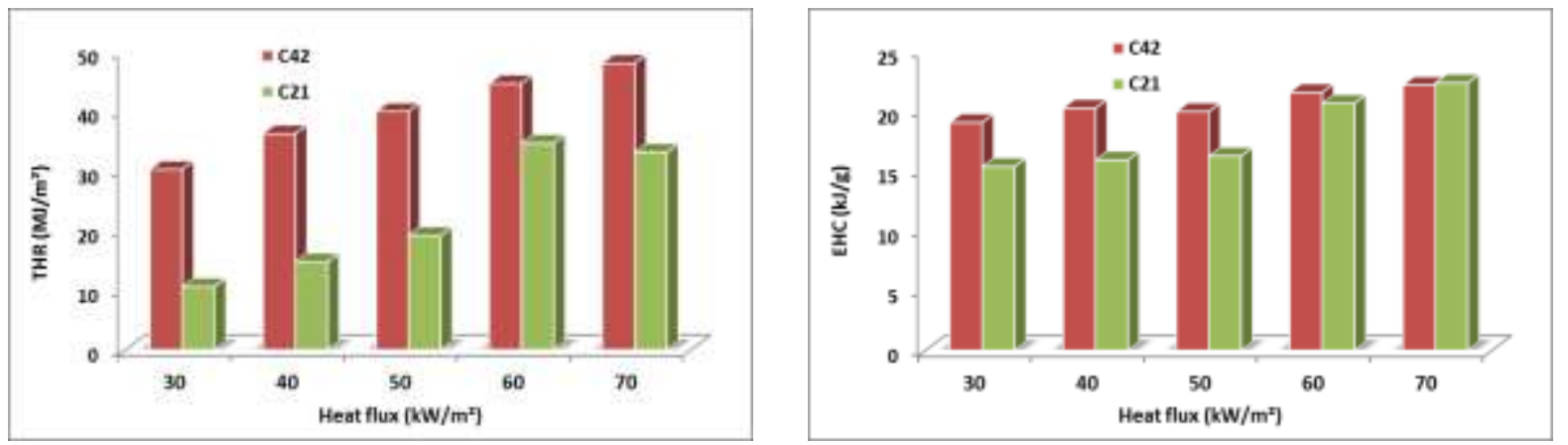

Figure 5. Total heat release and the effective heats of combustion for composite materials. 

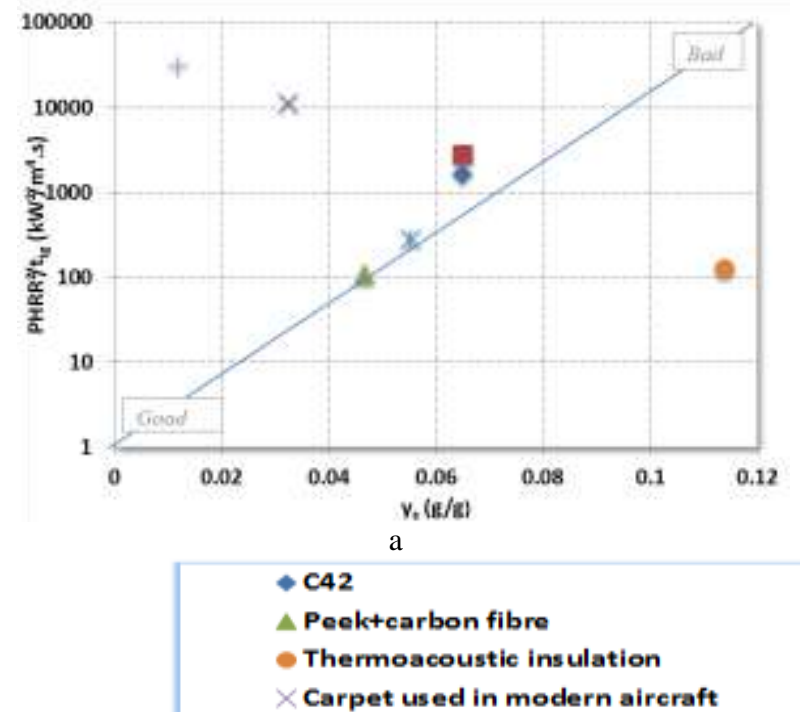

Figure 6. Classification of composites using the fire growth and smoke parameter.

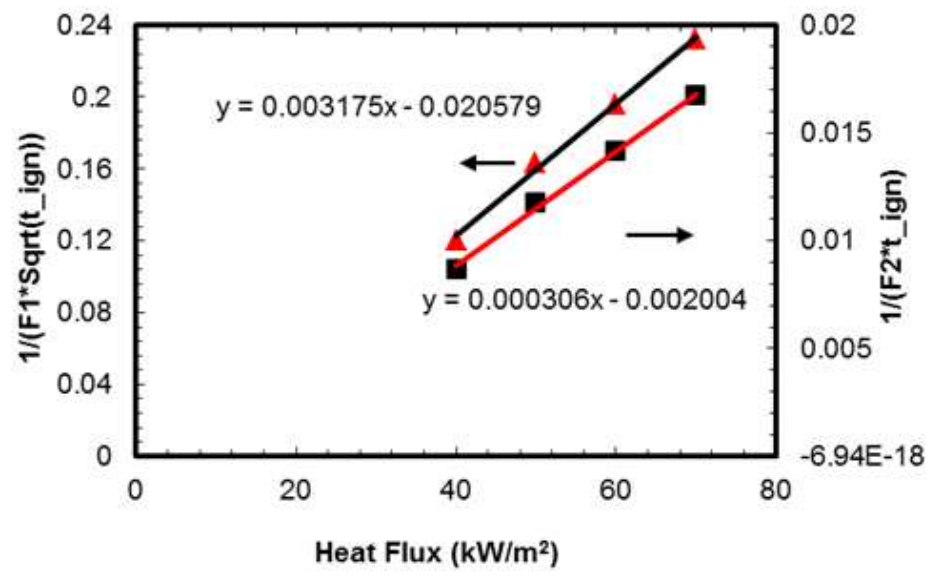

Figure 7. Determination of ignition properties by using relations of ignition times vs. external heat flux for $\mathrm{C} 42$ assuming thermally thick (left ordinate) and thermally thin conditions (right ordinate) [30-31]. 


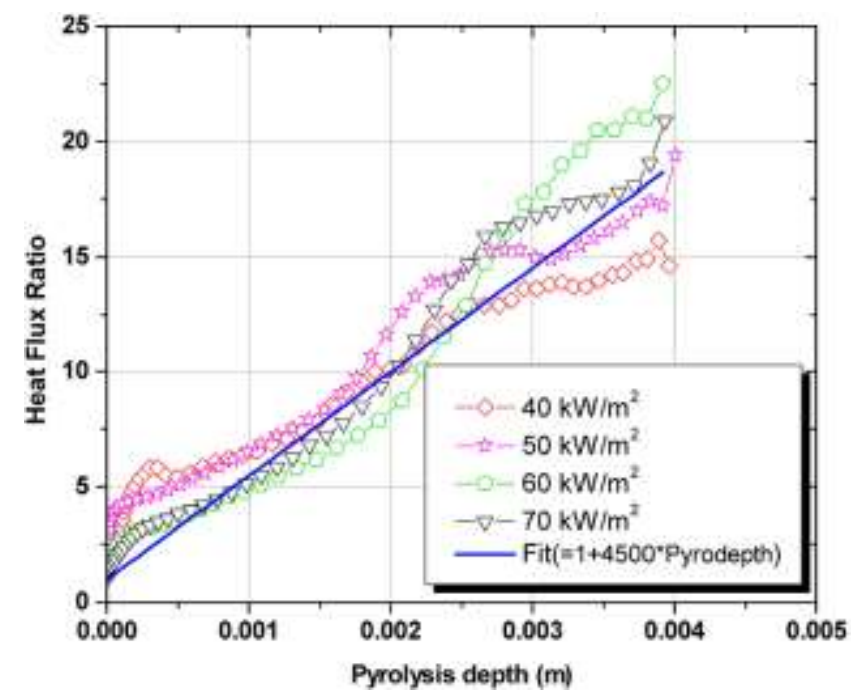

Figure 8. Deduced heat flux ratio against pyrolysis depth for $\mathrm{C} 42$ at different heat fluxes. The heat flux ratio is the net heat flux on the surface for the case when there is no surface CF shielding layer to the actual heat flux at the interface between the surface CF layer and the unpyrolysed material.

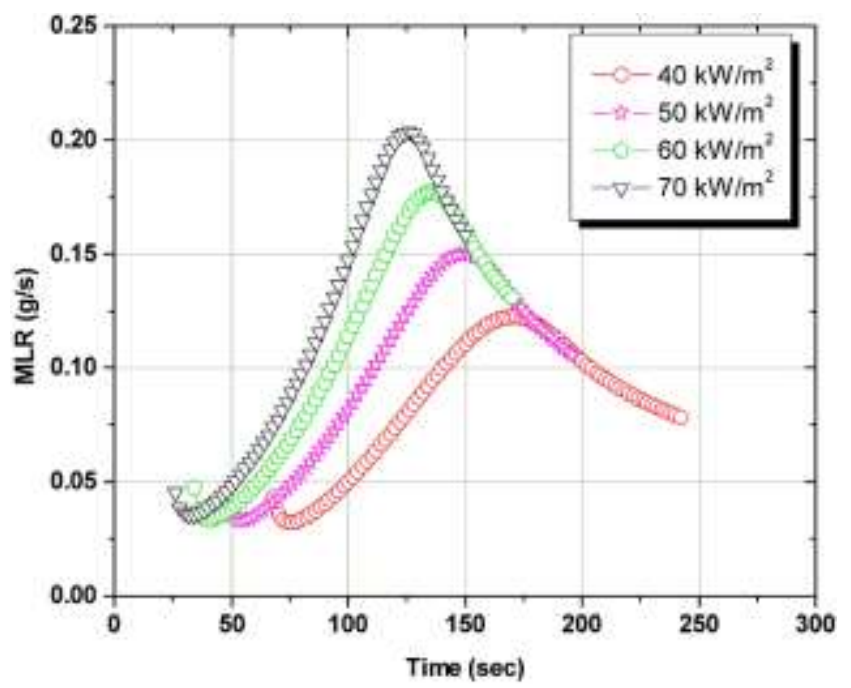

Figure 9. Predicted mass loss rate for C42 (thickness $4.2 \mathrm{~mm}$ ) at different heat fluxes. 

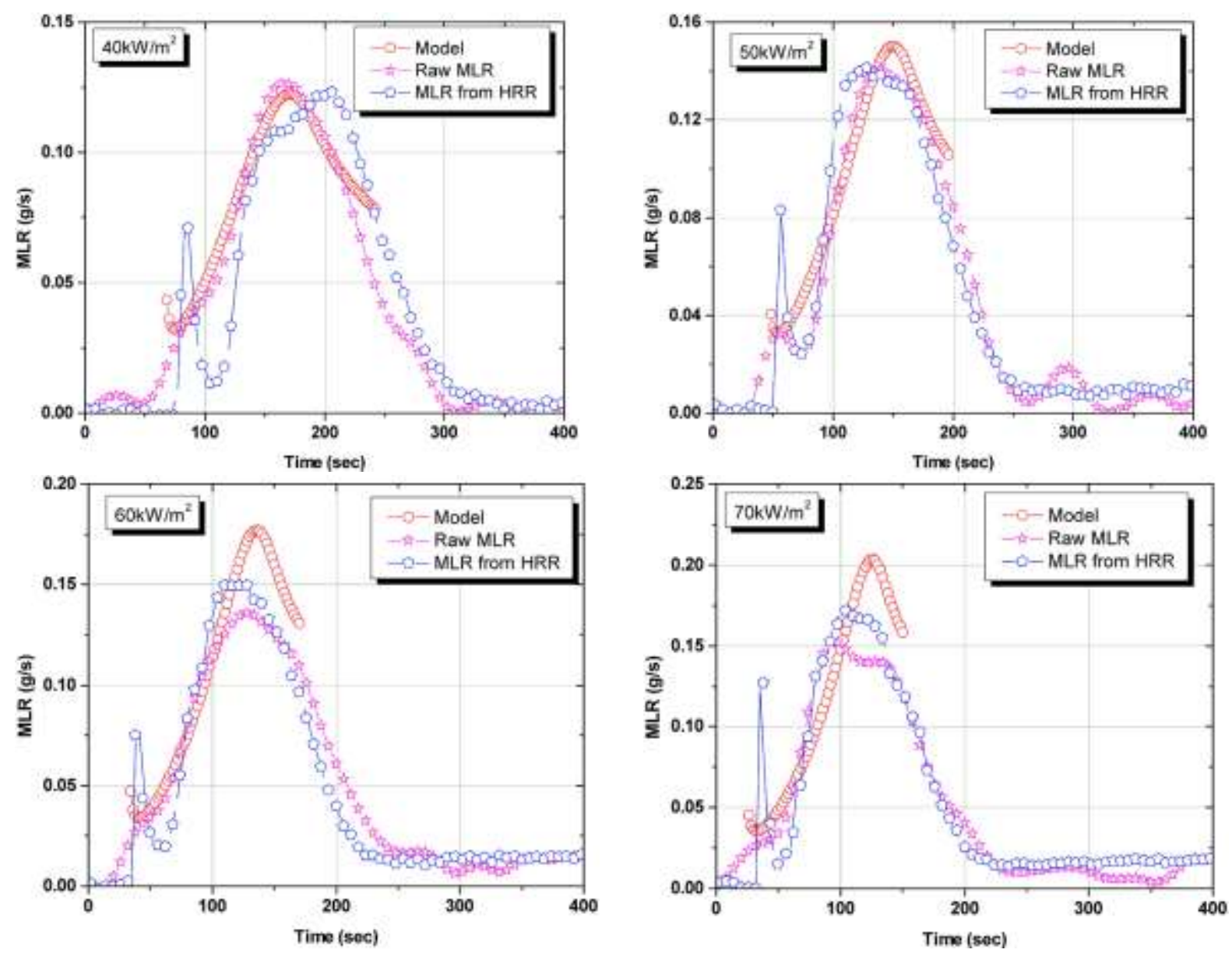

Figure 10. Comparison of experimental and predicted mass loss rate for C42 (thickness 4.2 $\mathrm{mm}$ ) at different heat fluxes.

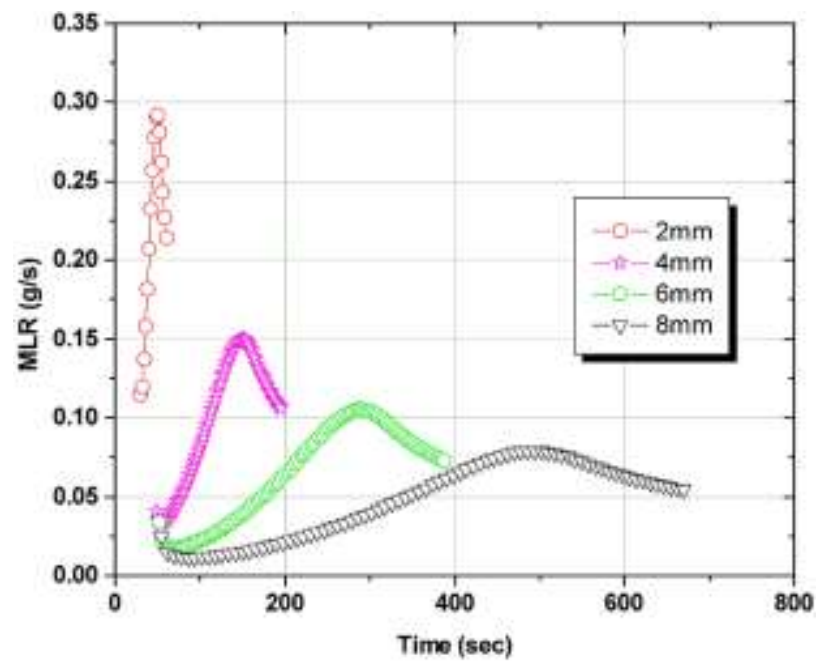


Figure 11. Predicted MLR for different thicknesses at $50 \mathrm{~kW} / \mathrm{m}^{2}$.
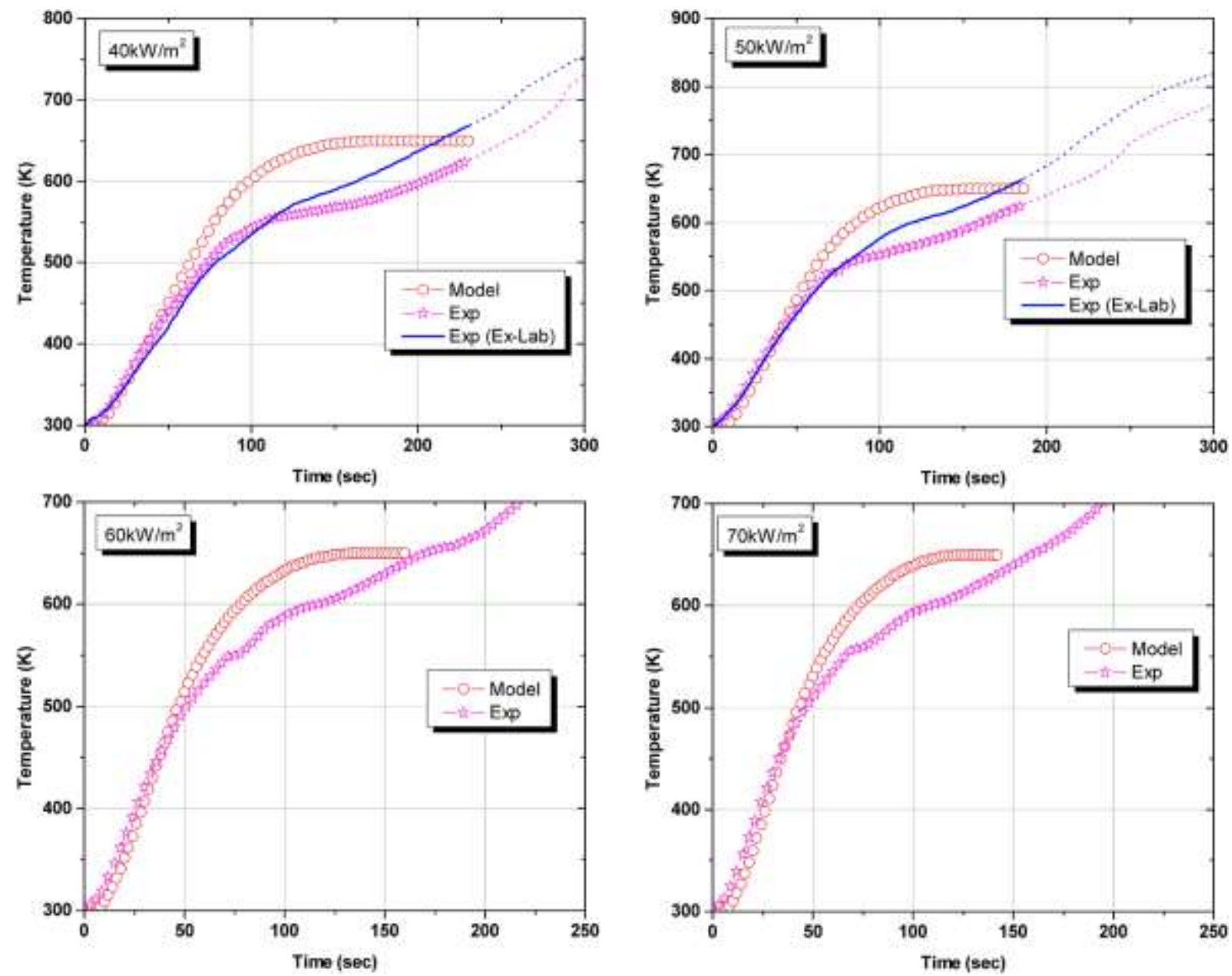

Figure 12. Comparison of experimental and predicted back side temperature for $\mathrm{C} 42$ at different heat fluxes. The experimental data include data in our lab and Institute P' for Ex-lab. 